\title{
INGUINAL HERNIA;
} MESH REPAIR RECURRENCE

Dr. Rashid Aslam, Dr. Habib Khan Shamsi, Dr. Ayaz Gul, Dr. Zahid Aman.

ABSTRACT... Objective: To find out the frequency of recurrence in inguinal hernia mesh repair in Surgical Unit, Khalifa Gulnawaz Teaching Hospital Bannu / DHQ, Bannu. Material \& Methods: 60 consecutive cases of inguinal hernia (direct/ indirect) of either side, in this study were repaired by Lichtenstein's repair. The study was conducted from January, 2010 to October, 2010 with an initial follow up of one year. Cases above 76 yrs were excluded from the study. Conclusions: The procedure of choice for inguinal hernia repair is tension free mesh repair.

Key words: Inguinal Hernia, Mesh Repair, Lichtenstein, Recurrence.

Article Citation

Aslam R, Shamsi HK, Gul A, Aman Z. Inguinal hernia; mesh repair recurrence. Professional Med J 2013;20(4): 562-565.

\section{INTRODUCTION}

A desire to decrease the recurrence rate of hernias has prompted an increase use of prosthetic materials in repair of both recurrent and first-time hernias. The most widely used technique is that of Lichtenstein ${ }^{1}$.

The Lichtenstein tension free hernioplasty involves placement of an approx $16 \times 8 \mathrm{~cm}$ (tailored to the individual patient's requirements) mesh as an extra lamina, anterior to the posterior wall and overlapping it generously in all directions including medially over the pubic tubercle ${ }^{2}$.

Reported recurrence rates vary between $02 \%$ to $15 \%$ depending on the technique employed. Only by using a meticulous technique, can a recurrence rate of less than $2 \%$ be achieved ${ }^{2}$. Recent trend in inguinal hernia surgery has been towards using a mesh based tension free repair ${ }^{3} \&$ Lichtenstein's repair of primary inguinal hernia is the most popular ${ }^{4}$, a well-established \& successful technique practiced by most surgeons ${ }^{5}$.

Many series of studies have been published showing the benefits of tension free mesh repair as a treatment of choice for inguinal hernia repair. Mesh technique \& the surgeon's experience are important factors to obtain good results. Never the less the risk of hernia recurrence increases from repair to repair ${ }^{6}$. It is now an established fact that classical Bassini repair of inguinal hernia produces unacceptably high recurrence rate ${ }^{7}$. This is also the case with plication darn repair irrespective of the experience of the operating surgeon ${ }^{8}$.

There has been a debate whether to perform an open or laparoscopic mesh repair. The latter is associated with less postoperative pain and early return to work, but it has the drawback of heavy cost, longer operative time \& a longer learning cure. The open method of mesh repair of inguinal hernia is simple, easy to learn \& has excellent results.

The present study aims at the surgical management of primary inguinal hernia by tension free mesh repair \& the determination of frequency of recurrence.

\section{MATERIAL AND METHODS}

60 consecutive cases of inguuinal hernia (direct/ indirect) of either side were operated in this study in Surg Unit KGNTH and DHQ Hospital Bannu, from Jan 2010 to October 2010, with an initial follow up of one year. Patients more than 18 years of age were included in this study. Patients younger than 18 years and those presenting with acute complications were excluded from the study. 
Patients were admitted throughout patient clinic, after taking detailed history, examination and relevant investigations. Assessment of the patient was done for general anesthesia fitness and after counseling, informed written consent was taken.

Patients were operated upon by senior consultants on elective list taking care of all the aseptic measures including sterilization and pre-op administration of antibiotic ( $3^{\text {rd }}$ generation Cephalosporin). The dose was repeated every 12 hours. Post operatively the wound was examined everyday for any complication.

\section{RESULTS}

All 60 cases included in study were male. Age range was 20 to 60 years, with mean age of 47.36 years $\pm 10.23 S D$. Most of the patients $n=21(35 \%)$ were between 50-59 years, of age group which was followed by age group 40-49 years with $n=19$ (31.6\%), age group $30-39$ years $n=8(13.3 \%)$, age group $60-69$ years with $n=10(16.6 \%)$ and age group $20-29$ years with $n=02(3.33 \%)$.

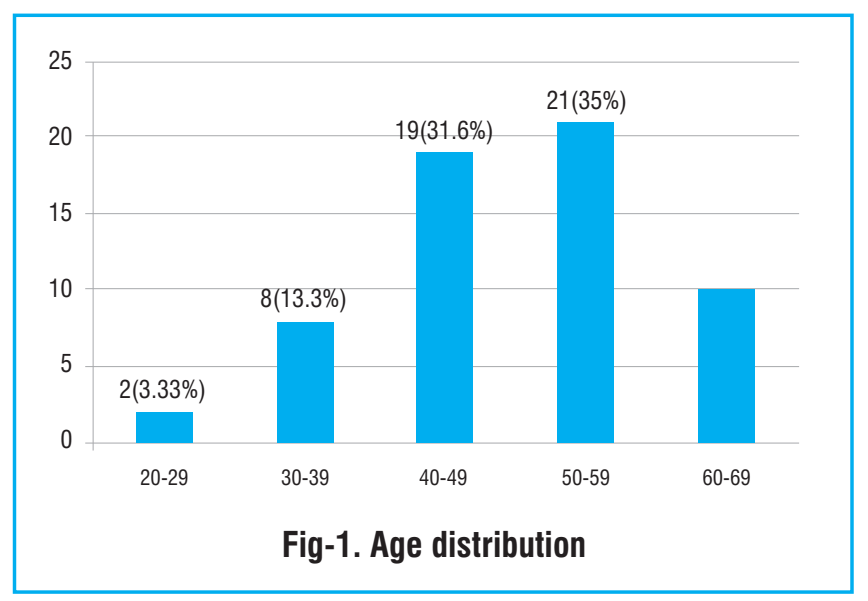

It was also found that out of all patients. $n=42(70 \%)$ Patients had inguinal hernia on right side in which $\mathrm{n}=$ $29(48.33 \%)$ patients had indirect \& $n=13(21.66 \%)$ patients had direct hernia. Similarly $n=18(30 \%)$ patients had left inguinal hernia out of which $n=12$ (20\%) patients had indirect inguinal hernia \& $n=6$
(10\%) patients had directhernia. (table I)

\begin{tabular}{|l|c|c|c|}
\hline \multirow{2}{*}{} & \multicolumn{2}{|c|}{ Side } & \multirow{2}{*}{ Total } \\
\cline { 2 - 3 } & Right & Left & \\
\hline Direct & $13(21.66 \%)$ & $6(10 \%)$ & $19(31.66 \%)$ \\
\hline Indirect & $29(48.33 \%)$ & $12(20 \%)$ & $41(68.33 \%)$ \\
\hline Total & $42(70 \%)$ & $18(30 \%)$ & $100(100 \%)$ \\
\hline \multicolumn{3}{|c|}{ Table-I. } \\
\hline
\end{tabular}

Out of all cases $n=46$ (76.6\%) belonged to an occupation associated with physical exertion like labours, loaders, cart drivers, welders etc \& only $n=14(23.3 \%)$ patients belonged to an occupation which is not associated with exertion like officers, workers, teachers, drivers etc.

Fifty four patients $n=54$ (90\%) had smooth early post operative recovery, $n=3(33 \%)$ patients had minor wound infection which was dealt with daily dressing \& antibiotics, $n=2(33 \%)$ patients had scrotal edema which was also resolved with conservative measures.

At one year follow up recurrence of inguinal hernia was found in $n=3(5 \%)$ patients.

\section{DISCUSSION}

Inguinal hernia is common problem. There is rapid increase of using mesh in inguinal hernia repair world wide and it is associated with low recurrence rates ${ }^{9}$. The Lichtenstein's repair of inguinal hernia was shown to have recurrence rates tenfold lower than those of the Shouldice repair ${ }^{10}$. Synthetic mesh not only reduces tension over the tissues avoiding postoperative pain and risk of the recurrence, it also induces synthesis of collagen by inducing an inflammatory response and setting up a scaffolding effect ${ }^{11}$.

We operated 60 consecutive inguinal hernia patients with mesh repair. All were male patients. The age range was from $20-70$ years. Our study shows that only males had suffered and it was virtually a disease of 
male patients. This has also been shown by some other studies ${ }^{12,13,14}$. Majority of the patients belonged to professions associated with heavy physical work, weight lifting or exertion.

We routinely use general anesthesia for inguinal hernia repair because of comfort of the patients and to avoid the risk of conversion to general anesthesia ${ }^{15}$. Many surgeon prefer local anesthesia for inguinal hernia repair $^{16,17,18}$. In over study 2 cases of seroma formation were detected constituting $3.3 \%$ of the total, while in some other studies it was reported to be $1.6 \%$ by Holheimer ${ }^{19}$ and $12.6 \%$ by Awad SS et al. ${ }^{20}$.

Minor wound infection was noted in 3 cases constituting $3.3 \%$ of the total, which responded well to local dressing and antibiotics. In one study conducted by Tseng $\mathrm{CC}$ et $\mathrm{al}^{17}, 9$ cases of wound infection were observed out of 1411 cases.

Recurrence remains the most frequent complication of hernia repair. In our study only $n=3(5 \%)$ patients had recurrence of inguinal hernia in initial one year follow up. A study conducted by Balen MF reported a 3.4\% incidence of hernia recurrence ${ }^{21}$.

Another study conducted by Jacobs reported recurrence rate in open repair (4\%) as compared to laparoscopic repair (10\%) ${ }^{22}$.

\section{CONCLUSIONS}

The procedure of choice for inguinal hernia repair (both primary \& recurrent) is tension free mesh repair. It has got minimum recurrence rate and relatively early \& pain free recovery.

\section{Copyright@ 28 Mar, 2013.}

\section{REFERENCES}

1. Way LW, Doherty GM, Hernias \& other lesions of the abdominal wall. In: Way LW, Doherty GM current surgical diagnosis \& treatment. 11th ed New York: Mc Graw Hill 2003; 783-96.
2. Iqbal P, Sheikh NA. Postoperative complications of inguinal hernia repair. Med Channel 2006;12:33-5.

3. Weber G, Csontos Z, Horvath OP, Magy Seb. Hernia Surgery in Hungary today; effect of the Lichtension-study 2006;59:405-10.

4. Aufenacker TJ, Koelemay MJ, Gouma DJ, Simons MP. Systematic review and meta-analysis of the effectiveness of antibiotic prophylaxis in prevention of wound infection after mesh repair of abdominal wall hernia. Br J Surg 2006; 93: 5-10.

5. Richards SK, Earnshaw JJ. Management of primary and recurrent inguinal hernia by surgeons from the South West of England. Ann R Coll Surg Engl 2003; 85: 402-4.

6. Khan M, Khan SM, Sharafat S, Khan Z. Inguinal herniorrhaphy with Vicryl darn: experience with 1150 cases. J Postgrad Med Inst 2006;20:44-7.

7. Liem MSL, van Duyn EB, Graaf YUD, van Vroonhoven TJM. Recurrences after conventional Anterior and Laparoscopic Inguinal Hernia Repair, A Randomized Comparison. Ann Surg 2003; 237: 136-141.

8. Culvert LL. Inguinal hernia repair. In: Senagore AJ, editor. Gale encyclopedia of surgery: a guide for patients and caregivers. Vol. 2. Detroit: Thomason Gale, 2004:752-7.

9. Atkinson HDE, Nicol S G, Purkayastha S, Paterson-Brown S. Surgical Management of inguinal hernia: retrospective cohort study in Southeastern Scotland, 1985-2001. BMJ 2004;329:1315-6.

10. Go PM. What is next in inguinal hernia surgery. Surg Technol Int 2006;15:116-9.

11. Gourgiotis S, Germanos S, Stratopoulos C, Moustafellos P, Panteli A, Hadjiyammakis E. Lichtenstein tension-free repair of inguinal hernia. Chirurgia (Bucur) 2006;101:509-12.

12. Palanivelu C, Rangarjan M, Jhon SJ. Modified technique of laparoscopic intraperitoneal Hernioplasty for irreducible scrotal hernias (omentoceles): how to remove the hernial contents. World J Surg 2007;31:1889-91. 
13. Shreshta SK,Sharma VK. Outcome of Lichtenstein operation: a prospective evaluation of sixty four patients. Nepal Med Coll J 2006; 8:230-3.

14. Farooq 0, Bashir-Ur-Rehman. Recurrent inguinal hernia repair by open preperitoneal approach. J Coll Physicians Surg. Pak 2005;15:267-5.

15. Farrakha M, Shyam V, Bebars GA, Yacoub M, Bindu K, Kolli S. Ambulatory inguinal hernia repair with prolene hernia system (PHS).

16. Pellisser E, Fingerhut A, Ngo P. Inguinal hernia, what techniques are available for the surgeon?Theoretical and practical advantages and disadvantages. J Chir (Paris) 2007; 102:433-8.

17. Tseng CC, Lin AD. Triple combined herniorrhaphy for inguinal hernia repair: experience of 1411 cases. Hepatogastroenteroenterology 2007; 54: 1433-7.

18. Truculet C, Feodor T, Dinescu G, Petrica R, Radulescu S, Beuran M. Bi-Layer Hernioplasty in day surgery. Chirurgia (Bucur) 2007; 102: 433-8.
19. Holzheimer RG. Low recurrence rate in hernia repair, results in $\mathbf{3 0 0}$ patients with open mesh repair of primary inguinal hernia. Eur $\mathrm{J}$ and Res 2007; 31: 1-5.

20. Awad SS, Yallampalli S, Srour AM, Bellows CF, Albo D, Berger $\mathrm{DH}$. Improved outcomes with the prolene hernia system mesh compared with the timehonored Lichtenstein onlay mesh repair for inguinal hernia repair. Am J Surg 2007; 193; 697-701.

21. Bringman S, Wollert S, Osterberg J, Smedberg S, Granlund H, Heikkinen TJ. Three-year results of a randomized clinical trial of lightweight or standard polypropylene mesh in Lichtenstein repair of primary inguinal hernia. Br J Surg 2006;93:1056-9.

22. Holzheimer $R G$. Low recurrence rate in hernia repair - results in $\mathbf{3 0 0}$ patients with open mesh repair of primary inguinal hernia. Eur J Med Res 2007;12:1-5.

\section{AUTHOR(S):}

1. DR. RASHID ASLAM

Senior Registrar

Khalifa Gul Nawaz Teaching Hospital,

Bannu, KPK, Pakistan

2. DR. HABIB KHAN SHAMSI

3. DR. AYAZ GUL

4. Dr. Zahid Aman
Correspondence Address:

Dr. Rashid Aslam

H. No. 394, St No. 27, D4 Phase-I

Hayatabad, Peshawar

drkk07@yahoo.com

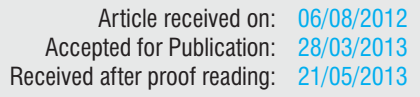

\section{PREVIOUS RELATED STUDIES}

Iftikhar Ahmed Bhatti. INGUINAL HERNIA REPAIR IN A PERIPHERAL HOSPITAL (Original) Prof Med Jour 13(4) 691-696 0ct, Nov, Dec, 2006.

Gulzar Ahmad Malik, Kashif Kurshid Qureshi, Imtriaz Ahmad, Muhammad Afzal. DARNING VS BASSINI REPAIR FOR INGUINAL HERNIA; A PROSPECTIVE COMPARATIVE STUDY (Original) Prof Med Jour 14(1) 134 - 143 Jan, Feb, Mar, 2007.

Muhammad Javed, Abdul Nasir. INGUINAL HERNIAS; COMPARISON OF OPEN PRE-PERITONEAL MESH REPAIR WITH LIECHTENSTEIN TENSION FREE REPAIR (Original) Prof Med Jour 13(4) 710-715 Oct, Nov, Dec, 2006.

Mirza Asadullah, Syed Hussein Mehdi, Sheeraz Shakoor Siddique. EARLY COMPLICATIONS OF INGUINAL HERNIA REPAIR (Original) Prof Med Jour 14(1) 119 - 122 Jan, Feb, Mar, 2007.

Shahzad Avais, M. Zakir, E. Rehman, Masood Rashid. INGUINAL HERNIA REPAIR; EXPERIENCE OF LAPAROSCOPIC TOTAL EXTAPERITONEAL APPROACH (Original) Prof Med Jour 17 (1) 35-39 Jan, Feb, Mar 2010.

Quddus-ur-Rehman, Tajammal Abbas Shah, Usman Latif. INGUINAL HERNIA; LICHTENSTEIN AND DARN REPAIR A COMPARATIVE STUDY (Original) Prof Med Jour 17(1) 50-54 Jan, Feb, Mar 2010. 